\title{
SURGICAL TREATMENT OF ASYMPTOMATIC AND MILDLY SYMPTOMATIC MITRAL REGURGITATION
}

Miguel Sousa Uva, $\mathrm{MD}^{\mathrm{a}}$

Gilles Dreyfus, $\mathrm{MD}^{\mathrm{b}}$

Giuseppe Rescigno, $\mathrm{MD}^{\mathrm{a}}$

Nadji Al Aile, $\mathrm{MD}^{\mathrm{b}}$

Roberto Mascagni, $\mathrm{MD}^{\mathrm{c}}$

Mauro La Marra, $\mathrm{MD}^{\mathrm{c}}$

Fréderic Pouillart, $\mathrm{MD}^{\mathrm{a}}$

Shirish Pargaonkar, $\mathrm{MD}^{\mathrm{a}}$

Evelyne Palsky, MD ${ }^{a}$

Radwan Raffoul, $\mathrm{MD}^{\mathrm{a}}$

Marcio Scorsin, $\mathrm{MD}^{\mathrm{a}}$

Giorgio Noera, $\mathrm{MD}^{\mathrm{c}}$

Arrigo Lessana, $\mathrm{MD}^{\mathrm{a}}$
Objective: The purpose of this study was to review the risk-benefit ratio of mitral valve repair in patients with severe mitral regurgitation and no or mild symptoms. Methods: From January 1989 to December 1994, 584 patients were operated on for mitral regurgitation. Of these, 175 patients were in New York Heart Association class I or II with grade 3 to 4 isolated chronic mitral regurgitation. They comprise our study population. Mean age was $51.3 \pm 14.3$ years. Principal causes of mitral regurgitation were degenerative in $128(73 \%)$ and rheumatic in 26 patients $(15 \%)$. Leaflet prolapse was the mechanism responsible for regurgitation in 152 patients $(86 \%)$. Mitral valve repair was performed in 174 patients, and one patient required initial valve replacement. Mean follow-up was $34.3 \pm 18.8$ months. Results: Three patients died, for an overall mortality of $1.7 \%$. Five patients were reoperated on, for an actuarial freedom from reoperation of $97.0 \% \pm$ $0.8 \%$ at 5 years. Actuarial freedom from thromboembolism and endocarditis was $96.3 \% \pm 1.7 \%$ and $99.4 \% \pm 0.6 \%$, respectively, for an event-free survival of $91.0 \% \pm 2.0 \%$ at 5 years. Left atrial diameter decreased from $54.3 \pm 11.6 \mathrm{~mm}$ to $43.6 \pm 10.5 \mathrm{~mm}(p<0.001)$. Left ventricular end-systolic and end-diastolic diameters decreased from $40.0 \pm 6.8 \mathrm{~mm}$ and $64.8 \pm 7.0$ $\mathrm{mm}$ to $34.6 \pm 6.7 \mathrm{~mm}(p<0.001)$ and $52.7 \pm 7.4 \mathrm{~mm}(p<0.001)$, respectively. Mean residual mitral regurgitation was $0.44 \pm 0.6$. Conclusion: Mitral valve repair for chronic mitral regurgitation in patients having mild or no symptoms was performed with low mortality and morbidity, good valve function, and preserved late left ventricular performance. Early repair may be advocated on the basis of severity of regurgitation and valve repairability, regardless of symptoms. (J Thorac Cardiovasc Surg 1996;112: 1240-9)
$T_{\mathrm{m}}^{\mathrm{h}}$ he optimal timing for surgical intervention in mitral regurgitation is still controversial. The difficulty in deciding when to operate on patients with chronic mitral regurgitation stems from the fact that mitral regurgitation may remain asymptomatic

From Hopital Européen de Paris La Roseraie, Aubervilliers, France, ${ }^{a}$ Hopital Foch, Suresnes, France, ${ }^{b}$ and Clinica Villa Maria, Cotignola, Italy. ${ }^{c}$

Read at the Seventy-sixth Annual Meeting of The American Association for Thoracic Surgery, San Diego, Calif., April 28-May 1, 1996.

Received for publication May 6, 1996; revisions requested June 6, 1996; revisions received July 8, 1996; accepted for publication July 10, 1996.

Address for reprints: Miguel Sousa Uva, MD, Department of Cardiac Surgery, Hôpital Européen de Paris La Roseraie, 120 Av de la Republique, 93308 Aubervilliers Cedex, France.

Copyright (C) 1996 by Mosby-Year Book, Inc.

$0022-5223 / 96 \$ 5.00+0 \quad \mathbf{1 2 / 6 / 7 6 3 3 6}$ or mildly symptomatic for a long time, albeit with progressive but silent deterioration in left ventricular (LV) function. ${ }^{1}$ By the time symptoms become apparent, serious and sometimes irreversible LV dysfunction may have developed. The absence of simple, load-independent LV function indexes also contributes to the difficulty in deciding when to operate on patients with mitral regurgitation and has stimulated the search for more discriminating and easy methods that could help in the optimal timing for surgery. ${ }^{2}$

Recognition of the advantages of valve repair over valve replacement for mitral regurgitation has progressively led to earlier surgical intervention., ${ }^{3,4}$ Most authors now advocate surgical intervention for severe mitral regurgitation even for patients in New York Heart Association (NYHA) class II so long as the ventricle is dilated and the valve seems repairable. ${ }^{5,6}$ Because echocardiography can reliably pre- 
Volume 112, Number 5

Table I. Causes of mitral regurgitation

\begin{tabular}{lrr}
\hline \multicolumn{1}{c}{ Cause } & No. & $\%$ \\
\hline Degenerative & 128 & 73 \\
Rheumatic & 26 & 15 \\
Endocarditis & 19 & 11 \\
Miscellaneous & 2 & 1 \\
\hline
\end{tabular}

dict the feasibility of valve repair, it has been our policy to surgically correct mitral valve insufficiency solely on the basis of the severity of regurgitation, irrespective of symptoms. ${ }^{7}$ However, the clinical impact of surgical correction of mitral regurgitation in patients with no symptoms or only mild symptoms is still uncertain in terms of outcome. Accordingly, we have reviewed our experience with the surgical management of isolated severe mitral regurgitation in patients with no symptoms or mild symptoms to assess the following: criteria for deciding on surgery, valve repair/replacement ratio, surgical as well as valve-related mortality and morbidity, and effect on late $\mathrm{LV}$ function.

\section{Patients and methods}

This study was based on a retrospective review of a three-institution experience with surgical correction of isolated mitral regurgitation in patients with no symptoms or mild symptoms. We reviewed the clinical case histories, operative notes, and laboratory investigations including electrocardiograms, echocardiograms, and cardiac catheterization data.

The inclusion criteria were as follows:

1. Surgical correction of mitral regurgitation between January 1989 and December 1994.

2. Preoperative functional class I or II according to the NYHA classification. The patient's functional status was determined by analysis of chart records. Patients were considered to have NHYA class I disease if they had no limitation of physical activity and no symptoms. NYHA class II was designated when there was slight limitation of physical activity with dyspnea on effort, for example, climbing more than one flight of ordinary stairs at a steady pace.

3. Isolated, severe mitral regurgitation with no or minimal associated mitral stenosis as defined by preoperative echocardiography.

The exclusion criteria were as follows:

1. Mitral regurgitation caused by dilated or ischemic cardiomyopathy.

2. Acute mitral regurgitation of recent onset with an episode of pulmonary edema occurring less than 3 months before the operation.

3. Associated or previous surgical procedures: coronary artery bypass grafting; valve replacement or repair other than tricuspid valve repair.

During the study period, 584 consecutive patients had mitral valve operations for mitral regurgitation in the three institutions; 520 patients had valve repair $(89 \%)$ and
Table II. Principal mechanisms of mitral regurgitation

\begin{tabular}{lcrr}
\hline \multicolumn{1}{c}{ Mechanism } & $\begin{array}{c}\text { Functional } \\
\text { type }\end{array}$ & No. & \multicolumn{1}{c}{$\%$} \\
\hline Restricted leaflet motion & I & 8 & 4.6 \\
Leaflet prolapse & II & 152 & 86.8 \\
& Anterior & 19 & \\
& Posterior & 86 & \\
Prolapse + restriction & Double & 47 & \\
Annular dilatation & III & 9 & 5.2 \\
Others & IV & 3 & 1.7 \\
\hline
\end{tabular}

64 had valve replacement $(11 \%)$. Of these, 175 patients did correspond to the inclusion-exclusion criteria, and they comprise our study population. Patients were operated on at Clinique La Roseraie $(n=73)$ and Hôpital Foch $(n=29)$, Paris, France, and Clinica Villa Maria $(n=$ 73), Cotignola, Italy, by two surgeons.

The mean age was $51.3 \pm 14.3$ years. There were 121 men $(69 \%)$ and 54 women. Fifty-three patients were in NYHA class I (30\%) and 122 were in NYHA class II (70\%). Data on preoperative medical treatment were available in 81 patients (46\%): $28 \%$ had no preoperative medical treatment, $40 \%$ had digitalis or diuretic therapy, and $32 \%$ had multiple drug therapy. Preoperatively, 123 patients were in sinus rhythm (70\%), 35 patients (20\%) were in atrial fibrillation, $15(9 \%)$ had prior episodes of atrial fibrillation, and in two patients information regarding the cardiac rhythm was unavailable. Patients with preoperative atrial fibrillation as compared with patients in sinus rhythm were older $(58.7 \pm 11.5$ years vs $49.4 \pm$ 14.4 years; $p<0.001)$ and had larger left atrial diameters $(61.6 \pm 13.0$ vs $52.6 \pm 9.4 \mathrm{~mm} ; p<0.001)$.

Causes of mitral regurgitation are listed in Table I. The mechanisms of mitral regurgitation are summarized in Table II according to the functional classification. ${ }^{8}$ The severity of mitral regurgitation was assessed either by LV angiography or transesophageal echocardiography. ${ }^{9}$ LV diameters and volumes were measured by transthoracic echocardiography in the parasternal long-axis view by the leading edge method. ${ }^{10} \mathrm{LV}$ ejection fraction was calculated as previously described. ${ }^{11}$ All patients had grade $3+$ or $4+$ mitral regurgitation on a scale of 4 with a mean of $3.4 \pm 0.5$. LV end-systolic and end-diastolic diameters were $40.0 \pm 6.8 \mathrm{~mm}$ and $64.8 \pm 7.0 \mathrm{~mm}$ (mean \pm standard deviation), respectively. Mean left atrial diameter was $54.3 \pm 11.6 \mathrm{~mm}$. Of 151 patients who had preoperative recording of end-diastolic diameter, $111(73 \%)$ had an LV end-diastolic diameter greater than 60 and 29 had an end-diastolic diameter greater than 70 (19\%). Forty-seven patients underwent preoperative right heart catheterization. The mean pulmonary artery pressure was $22.2 \pm 9.3$ $\mathrm{mm} \mathrm{Hg}$.

There were no significant differences between patients with NYHA class I or class II disease with regard to age, degree of regurgitation, or left heart chamber size except for LV end-diastolic diameter, which was smaller in patients with class II disease $(63.9 \pm 6.9 \mathrm{~mm}$ in NYHA class I vs $67.2 \pm 6.5$ in NYHA class II; $p=0.008$ ). 
Table III. Surgical procedures

\begin{tabular}{lrc}
\hline \multicolumn{1}{c}{ Procedures } & No. & $\%$ \\
\hline Posterior leaflet resection & 133 & 76 \\
Chordal transposition & 46 & 26 \\
Chordal shortening & 38 & 22 \\
Sliding repair & 14 & 8 \\
Subvalvular mobilization & 17 & 10 \\
Commissurotomy & 12 & 7 \\
Anterior leaflet patch & 2 & 1 \\
Annular decalcification & 2 & 1 \\
Ring annuloplasty & 174 & 100 \\
Tricuspid repair & 27 & 15 \\
Mitral valve replacement & 1 & 0.5 \\
\hline
\end{tabular}

No fixed protocol was followed, but in general the decision to operate was made when the following criteria were met: (1) Severe mitral regurgitation (grade 3 or 4 ) was recorded and appeared to induce progressive left atrial-LV dilatation or atrial arrhythmia (or both); (2) the patient was in good general condition without any other systemic diseases; and (3) the valve was deemed repairable by an experienced echocardiographer.

Of the 175 patients, 174 had initial mitral valve repair and one had valve replacement. Valve repair was attempted in all cases. In one patient, the decision to replace the valve was made during the operation because of severely retracted leaflets owing to rheumatic disease. Carpentier techniques were used for repair in all three institutions, ${ }^{12}$ with some modifications as previously reported, ${ }^{13}$ and are listed in Table III. A standard Carpentier-Edwards prosthetic ring (Baxter Healthcare Corp., Edwards Div., Santa Ana, Calif.) was used in 144 patients, and a flexible Carpentier-Edwards Physio ring (Baxter) was used in 28 patients. Mean crossclamp and cardiopulmonary bypass times were $62.8 \pm 15.5$ and $90.2 \pm 20.9$ minutes, respectively. All patients received systemic anticoagulation with antivitamin $\mathrm{K}$ therapy for the first 2 months after the operation. After this period, discontinuation of anticoagulation was recommended for patients in sinus rhythm, but the decision was left to the discretion of the referring physician.

Follow-up. Data were collected through questionnaires and telephone contacts with the patients, family physicians, and cardiologists. Long-term follow-up was obtained during a 6-month interval from July to December 1995. Follow-up was available for 167 patients $(98.1 \%)$. Mean follow-up was $34.3 \pm 18.8$ months (median $=26.5$ months) for a cumulative follow-up of 473 patient-years. Results were reported according to the recommendations of the Ad Hoc Liaison Committee as found in the "Guidelines for Reporting Morbidity and Mortality After Cardiac Valvular Operations."14

Statistical analysis. Data were expressed as mean \pm one standard deviation, and selected proportions were presented with their $70 \%$ confidence limits. $\chi^{2}$ Contingency tables and Student's $t$ test were used to analyze the significance of differences between preoperative and postoperative data. The Kaplan-Meier method was used for calculating the actuarial survival and complication rates.

\section{Results}

Mortality. Three patients died during the first 30 postoperative days, one at each of the institutions, for an overall hospital mortality of $1.7 \%$. Cause of death was LV failure in two patients aged 73 and 58 years, who had preoperative LV end-diastolic volume indexes of 132 and $190 \mathrm{ml} / \mathrm{m}^{2}$, respectively. Death in the third patient was due to a cerebral tumor hemorrhage occurring immediately after the operation. There were no late deaths. The actuarial survival at 5 years was $98.2 \% \pm 1.0 \%$ (Fig 1 ).

Morbidity. Six patients required reexploration for bleeding. One patient had ischemic cerebral infarction, which eventually resolved without sequelae 2 months after the operation. One patient required a permanent pacemaker for complete atrioventricular block. Two patients had systolic anterior motion of the anterior leaflet, detected on postoperative Doppler echocardiography, which was successfully treated pharmacologically. Thus a total of 10 patients had a significant morbid event for a cumulated mortality-morbidity rate of $7.4 \%$.

Reoperations. There were three early reoperations for failure of the valve repair during the immediate postoperative period. All three patients were in NYHA class II before the operation and had valve replacement for their failed repair. Causes for early reoperation were residual mitral insufficiency in two patients and LV outflow tract obstruction in another patient with Barlow's disease. There were two late reoperations at 3 and 5 months. The original etiology was rheumatic mitral disease in one patient and degenerative valve disease in the other patient. Causes for reoperation were significant residual leak caused by persistent restricted leaflet motion in one case and ring dehiscence in the second case, and both necessitated valve replacement. No deaths occurred during reoperation.

At 5 years, the rate of freedom from reoperation was $97.0 \% \pm 0.8 \%$, for a linearized rate of $1 \% / \mathrm{pt}-\mathrm{yr}$ exposed to reoperation.

Thromboembolism. Five patients had a thromboembolic event, for an actuarial rate of freedom from thromboembolic complications of $96.2 \% \pm$ $1.7 \%$ at 5 years and a linearized rate of $1.0 \% / \mathrm{pt}-$ yr. One patient had an asymptomatic left atrial thrombus diagnosed by two-dimensional echocardiography. Two patients had transient amaurosis. Two patients had hemiparesis that resolved without residual deficit.

Anticoagulant-related hemorrhage. Apart from the already mentioned intracerebral tumor hemor- 


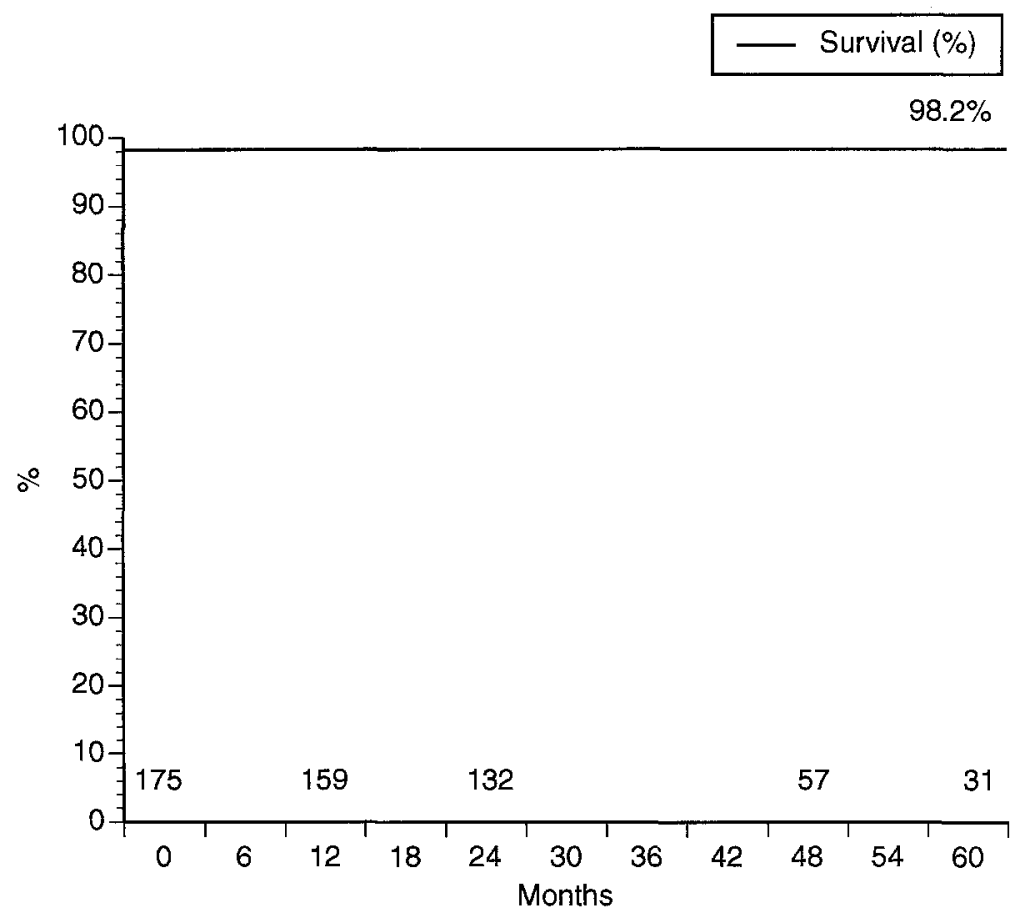

Fig. 1. Actuarial survival curve (percent) as a function of time after the initial operation. Numbers above $x$ axis represent number of patients available for follow-up.

rhage, no anticoagulant-related complication was seen in this series. Twenty-five patients were receiving long-term anticoagulant therapy $(15.5 \%)$ at most recent follow-up.

Endocarditis. One patient had valvular endocarditis and was treated with antibiotics, for an actuarial rate of freedom from endocarditis of $99.3 \% \pm$ $0.6 \%$ at 5 years and a linearized rate of $0.2 \% / \mathrm{pt}-\mathrm{yr}$.

Event-free survival. Freedom from death, thromboembolism, reoperation, and anticoagulant-related hemorrhage was $91.0 \% \pm 2.0 \%$ at 5 years (Fig 2).

Cardiac rhythm. In 162 patients the electrocardiogram was analyzed at the most recent visit. Twenty-three patients were in atrial fibrillation $(14.1 \%), 134$ were in sinus rhythm (83.3\%), and five patients had other cardiac rhythms. Ten patients who were in sinus rhythm before the operation had atrial fibrillation at the most recent visit, whereas 17 who were in atrial fibrillation before the operation had sinus rhythm during follow-up (Fig. 3).

Functional status. A total of 145 patients were in NYHA class I $(86.8 \%), 21$ were in NYHA class II $(12.5 \%)$, and one patient was in NYHA class III $(0.5 \%)$. In 150 patients, information could be obtained regarding medical therapy. One hundred four patients $(69.3 \%$ ) had no medical therapy (vs $28 \%$ before the operation); 27 patients were receiving one medication (18.0\%) and 19 patients (12.6\%) were on a double drug regimen.

Echocardiographic results. Two-dimensional echocardiography and Doppler examination were available in 140 patients at latest follow-up (83.3\%). The echocardiographic data before and after operation showed that all left heart chamber dimensions decreased significantly. These are summarized in Table IV. Eightytwo percent (110/134) of the patients had an endsystolic LV diameter less than $40 \mathrm{~mm}$. Indexed LV diameters were significantly smaller at most recent follow-up than they had been before the operation $(p<0.001)$ (Fig. 4). The mean grade of residual mitral regurgitation as recorded at late follow-up was $0.44 \pm$ 0.6. Only nine patients $(6.4 \%)$ had grade 2 residual mitral insufficiency or greater. In all but one of these nine patients, the left atrial and LV sizes had reverted to normal and they received no medical therapy.

Posterior versus bileaflet prolapse. Aortic crossclamping time for repair of bileaflet prolapse was longer than that for correction of posterior prolapse alone $(69.7 \pm 15.3$ minutes vs $55.3 \pm 12.1$ minutes; $p<0.001)$. However, no significant difference could be demonstrated between patients with posterior leaflet prolapse and those with anterior and poste- 


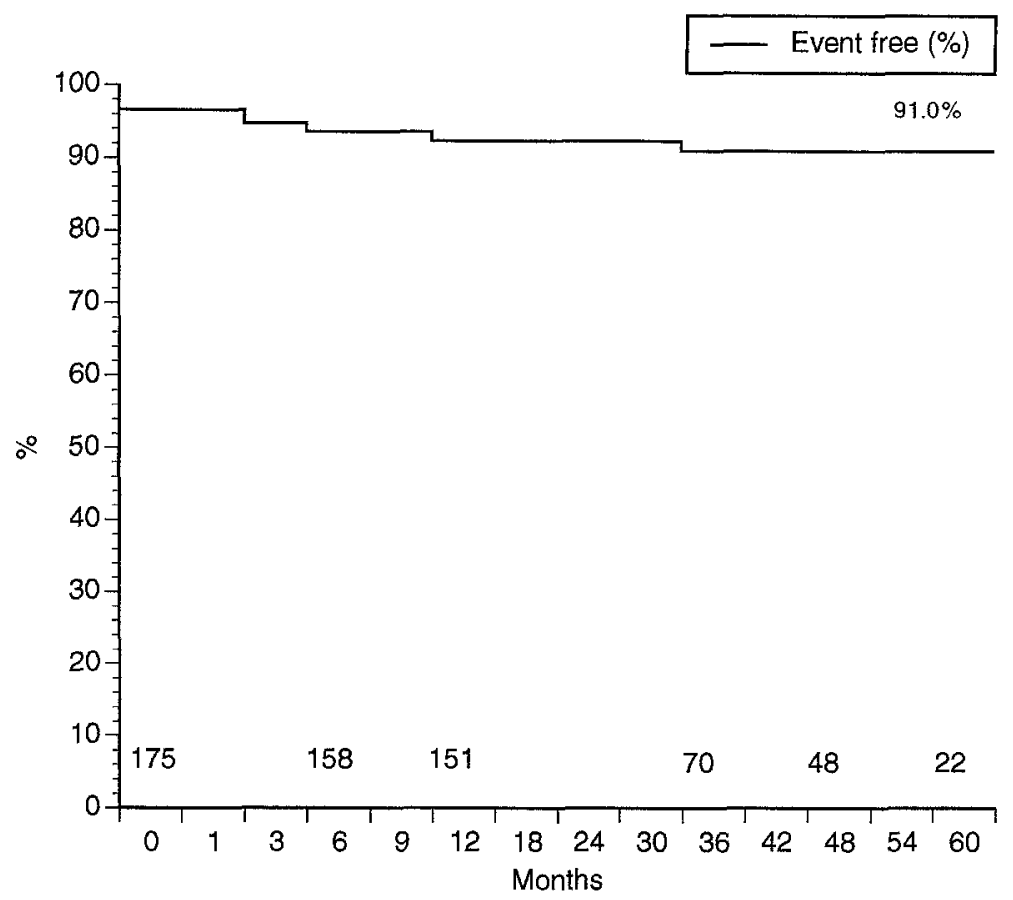

Fig. 2. Actuarial curve of patients free from death and valve-related complications (percent) as a function of time after the initial operation (months). Numbers above $\mathrm{x}$ axis represent number of patients available for follow-up.

rior prolapse regarding incidence of repair, residual leak, reoperation rate, and ventricular diameters.

Degenerative versus rheumatic mitral regurgitation. Comparison of clinical findings and postoperative results in patients with degenerative versus rheumatic disease showed that the patients with rheumatic disease were younger, had a greater degree of residual regurgitation, higher transmitral gradients, and larger left atrial diameters. However, patients with rheumatic disease had smaller late postoperative end-diastolic diameters (Table V).

\section{Discussion}

The ultimate goal of surgical therapy for mitral regurgitation is to provide symptomatic relief and increased life expectancy at the lowest rate of complications. However, it is difficult to make a symptom-free patient feel better, and consideration must therefore be given to other parameters influencing the late outcome. As for any medical intervention, indications should be based on weighing risk against benefit. Surgical correction may be advised only if survival and quality of life are improved in comparison with the disease's natural course. In this study,
175 patients with severe chronic mitral regurgitation and no or mild symptoms underwent an operation; $171(98 \%)$ had valve repair, with three deaths $(1.7 \%)$, for an actuarial survival of $98.2 \%$ and an event-free survival of $91.0 \%$ at 5 years.

Population. In this series, patients in NYHA classes I and II had similar LV diameters before the operation, which confirms the poor reliability of the functional classification to identify patients at risk for the development of $\mathrm{LV}$ dysfunction. ${ }^{15}$ The causes of mitral insufficiency in this series were representative of most western countries, with a predominance of degenerative disease and a low incidence of rheumatic valvular disease. ${ }^{16,17} \mathrm{~Pa}$ tients with associated coronary disease were excluded to avoid interfering variables.

Decision-making. The decision to operate was based on assessment of the severity of mitral regurgitation and the feasibility of repair. Severity was judged by angiographic or Doppler parameters, echocardiographic left heart dimensions, and pulmonary artery pressure. Clinical parameters such as physiologic age, associated disease, lifestyle, and episodes of atrial fibrillation were also carefully 


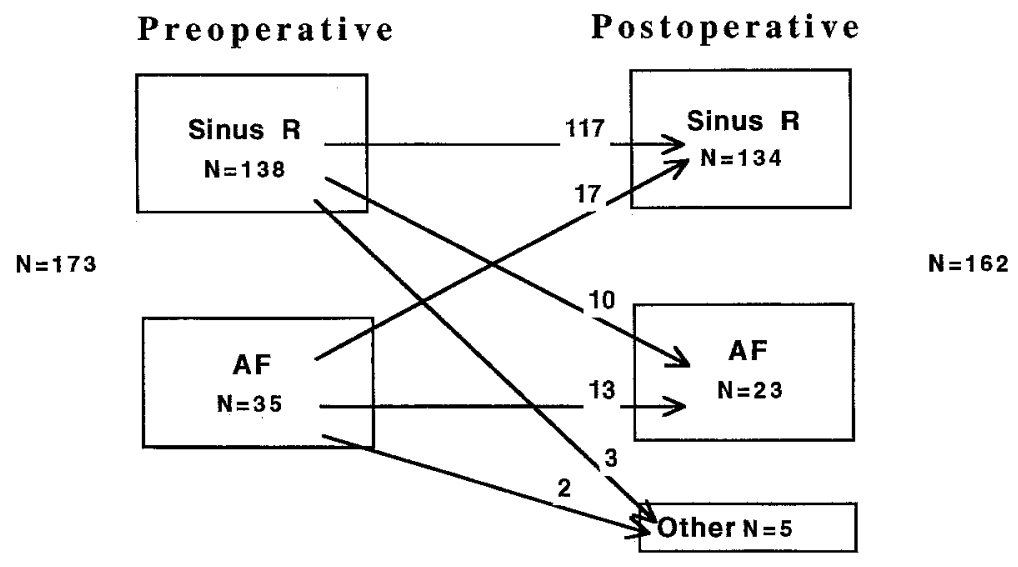

Fig. 3. Cardiac rhythm before the operation and at latest visit. $A F$, Atrial fibrillation.

pondered. In this series, the mean preoperative end-systolic and end-diastolic LV diameters of, respectively, 40 and $65 \mathrm{~mm}$, were lower than the guidelines suggested in the literature. ${ }^{6,15,18}$ This probably reflects our referring cardiologists' belief in the benefits of early surgical referral even for minimally disabled patients with severe chronic mitral insufficiency. Ability to distinguish between valves amenable to repair and those that are likely to require replacement is the cornerstone in the process of deciding the timing of operation. In this study, as in previous reports, preoperative twodimensional echocardiography reliably predicted the feasibility of mitral valve repair. ${ }^{7,} 19$ Indeed, only four patients (2\%) required valve replacement when taking into account the three patients who underwent early reoperation for failed repair. Main echocardiographic features that decrease the likelihood of valve repair are anterior leaflet rigidity and restricted motion, particularly with a small anterior leaflet surface area. Calcification per se is not an absolute contraindication so long as it spares the leaflets, but it makes valve repair less predictable. Finally, what counts most in determining the feasibility of repair is the surgeon's personal experience with mitral valve reconstruction.

Surgery. In the large majority of our patients $(86 \%)$, mitral regurgitation was due to leaflet prolapse, in accordance with the predominance of degenerative valve disease in this series. Correction of anterior leaflet prolapse required the use of chordal transposition or chordal shortening in $26 \%$ and $22 \%$ of the cases, respectively. Correcting extreme forms of Barlow's disease with bileaflet pro-
Table IV. Echocardiographic data

\begin{tabular}{lccc}
\hline & Preoperative & Follow-up & p Value \\
\hline ESD & $40.0 \pm 6.8$ & $34.6 \pm 6.7$ & 0.001 \\
IESD & $22.0 \pm 4.0$ & $19.2 \pm 3.8$ & 0.001 \\
EDD & $64.8 \pm 7.0$ & $52.7 \pm 7.4$ & 0.001 \\
IEDD & $35.9 \pm 4.7$ & $29.3 \pm 3.9$ & 0.001 \\
ESVI & $40.0 \pm 14.3$ & $75.6 \pm 20.7$ & 0.001 \\
EDVI & $120.0 \pm 25.9$ & $43.6 \pm 10.5$ & 0.001 \\
LAD & $54.3 \pm 11.6$ & $43.6 \pm 10.5$ & 0.001 \\
EF & $64.3 \pm 10.5$ & $62.7 \pm 8.8$ & NS \\
MR & $3.4 \pm 0.5$ & $0.44 \pm 0.6$ & 0.001 \\
\hline
\end{tabular}

$E F$, Ejection fraction (\%); ESD, left ventricular end-systolic diameter $(\mathrm{mm}) ; I E S D$, indexed left ventricular end-systolic diameter $\left(\mathrm{mm} / \mathrm{m}^{2}\right)$; $E D D$, left ventricular end-diastolic diameter $(\mathrm{mm}) ; I E D D$, indexed left ventricular end-diastolic diameter $\left(\mathrm{mm} / \mathrm{m}^{2}\right) ; E S V I$, left ventricular endsystolic volume index $\left(\mathrm{ml} / \mathrm{m}^{2}\right) ; E D V I$, left ventricular end-diastolic volume index $\left(\mathrm{ml} / \mathrm{m}^{2}\right) ; L A D$, left atrial diameter $(\mathrm{mm}) ; M R$, mitral regurgitation (mean; grade 1 to 4 )

lapse and frequently commissural prolapse usually requires the combination of several techniques, as confirmed in the present study by the longer crossclamp times in these patients compared with those with simple posterior prolapse. ${ }^{20}$ Most important, the same spectrum of functional disorders and the same degree of reconstruction complexity can be found in the minimally disabled as in the more severely symptomatic patient.

Survival. Few studies on the natural history of mitral regurgitation have been conducted. Ramanathan and associates ${ }^{21}$ reported nine deaths $(22 \%)$ among 41 patients with pure mitral regurgitation in functional classes I and II during a 4-year follow-up. Delahaye and colleagues, ${ }^{22}$ describing 32 patients with severe mitral regurgitation who were 

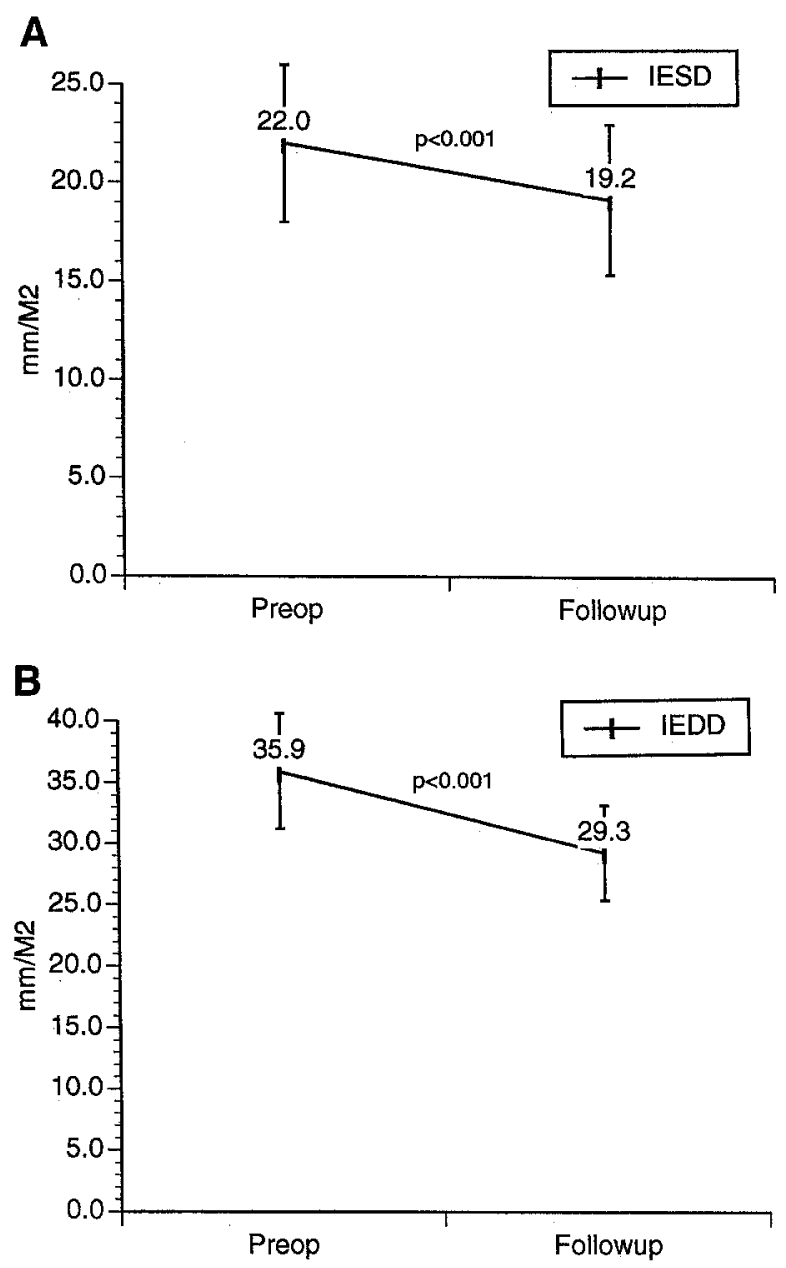

Fig. 4. Mean indexed LV diameters before the operation and at latest follow-up measured by echocardiography. A, Indexed end-systolic diameter (IESD) (mm). B, Indexed end-diastolic diameter (IEDD) (mm).

not considered candidates for surgical repair as yet, reported seven deaths $(22 \%)$, four of them sudden. These authors also demonstrated that despite an ejection fraction greater than $45 \%$, the risk of cardiac death was not eliminated, because they found a $29 \%$ incidence of sudden death.

Although our population may differ from the ones reported in the aforementioned studies, a survival of $98 \%$ at 5 years observed in the present series compares favorably with the natural history of the disease. Reports on mitral valvuloplasty indicate an actuarial survival around $90 \%$ at 5 years for populations with predominantly functional class III and IV disease. ${ }^{23-25}$ Interestingly, in all these series, about half of late deaths were of cardiac origin, caused by congestive heart failure or arrhythmias. Also, it has recently been
Table V. Degenerative versus rheumatic mitral regurgitation

\begin{tabular}{|c|c|c|c|c|c|}
\hline & \multicolumn{2}{|c|}{$\begin{array}{c}\text { Degenerative } \\
(n=26)\end{array}$} & \multicolumn{2}{|c|}{$\begin{array}{l}\text { Rheumatic } \\
(n=128)\end{array}$} & \multirow[b]{2}{*}{$p$ Value } \\
\hline & Mean & $S D$ & Mean & $S D$ & \\
\hline Age & 53.7 & 12.9 & 41.15 & 16.3 & $<0.0001$ \\
\hline Preop. ESD & 39.8 & 5.9 & 40.5 & 5.7 & NS \\
\hline Preop. EDD & 65.1 & 7.2 & 63.6 & 5.8 & NS \\
\hline Preop. EF & 65.3 & 10.8 & 60.0 & 7.4 & $<0.09$ \\
\hline Clamp time & 62.4 & 16.0 & 63.7 & 16.5 & NS \\
\hline Postop. LAD & 42.8 & 10.3 & 49.8 & 9.6 & $<0.007$ \\
\hline Residual MR (1-4) & 0.34 & 0.59 & 0.95 & 0.67 & $<0.0001$ \\
\hline Postop. ESD & 35.3 & 6.5 & 32.8 & 4.1 & NS \\
\hline Postop. EDD & 53.7 & 6.4 & 49.9 & 4.5 & $<0.01$ \\
\hline Postop. EF & 62.5 & 9.2 & 63.0 & 6.64 & NS \\
\hline Mitral gradient & 3.2 & 1.9 & 4.5 & 1.7 & $<0.006$ \\
\hline
\end{tabular}

$E S D$, Left ventricular end-systolic diameter; $E D D$, left ventricular enddiastolic diameter; $E F$, ejection fraction; $L A D$, left atrial diameter; $M R$, mitral regurgitation.

shown that in patients with mitral regurgitation, preoperative functional class remained an independent predictor of operative and late survival. ${ }^{26}$

Morbidity and valve-related complications. A low rate of perioperative complications was observed in this series, the majority of them being minor. Had intraoperative transesophageal echocardiographic monitoring been available in this study, the three early reoperations probably could have been avoided. One of these reoperations was necessitated by systolic anterior motion of the anterior leaflet in a patient with myxomatous degeneration and occurred before we began using the sliding leaflet repair, a technique that has virtually eliminated this complication. ${ }^{27}$ Sequential postoperative Doppler echocardiographic studies showed that mitral valve repair was stable and durable, inasmuch as most patients $(93 \%)$ in our series had minimal or no mitral regurgitation at late follow-up. Residual regurgitation was more prevalent in patients with rheumatic disease, an observation that probably should lead to a more conservative approach, particularly with restricted motion of the anterior leaflet. $^{20,23}$ On the other hand, in our experience, bileaflet prolapse, although requiring specific techniques, had the same incidence of reoperation or residual regurgitation as the more straightforward posterior prolapse.

The $96.3 \% \pm 1.7 \%$ rate of freedom from thromboembolism and the absence of anticoagulant-related complications, for an event-free survival of $91 \%$ at 5 years, are undisputable indicators of low valve-related morbidity. Moreover, significant re- 
duction in left atrial size may account for the $83 \%$ incidence of sinus rhythm at follow-up (vs $70 \%$ before the operation) and the low incidence of thromboembolic complications.

LV function. True functional improvement was demonstrated in this study inasmuch as the percentage of patients in NYHA class I rose from $30 \%$ to $87 \%$ as did the percentage of patients requiring no medical therapy, from $28 \%$ to $69 \%$. Another finding of this study was the significant decrease in LV end-systolic and end-diastolic diameters and indexed LV volumes to normal values in almost all patients. Similar results were obtained by other investigators using cineangiography or echocardiography. ${ }^{28,29}$ Several reports have demonstrated the prognostic value of end-systolic LV dimensions and ejection fraction. ${ }^{18,30}$ Borow and coworkers ${ }^{30}$ showed that patients with mitral regurgitation who had an end-systolic volume index in excess of normal $\left(>31 \mathrm{ml} / \mathrm{m}^{2}\right)$ had abnormal postoperative LV function, proportional to the degree of enlargement. Postoperative ejection fraction has been shown to correlate well with outcome and to be predicted by preoperative echocardiographic ejection fraction as well as systolic LV diameter. ${ }^{31}$ In the present series, $82 \%$ of the patients had late LV systolic dimensions within normal range. Thus mitral valvuloplasty, in the absence of severe symptoms, achieved the goal of preserving postoperative LV function and should guarantee an excellent late outcome.

Limitations. No information could be gathered about the number of patients with minimal impairment who were not referred for surgical treatment because their mitral regurgitation was deemed unrepairable. The functional NYHA classification has recognized limitations that may have blurred the inclusion process. Ideally, patients should have been objectively assessed with a standardized exercise test or measurement of peak oxygen consumption. Clear demonstration of the superiority of surgical treatment for patients with no symptoms or mild symptoms would theoretically require a randomized trial comparing the outcomes of medically and surgically treated patients. However, it would have been impractical to gather such a control group in our medical environment because the majority were referred for surgical treatment.

\section{Conclusions}

Surgical treatment can be advocated for severe mitral regurgitation regardless of symptoms, because valve repair can be accurately predicted and performed in a large majority of patients with a low mortality and morbidity. An event-free survival of $91 \%$ at 5 years, combined with a significant reduction in left heart dimensions, low incidence of atrial arrhythmias, and residual leak, suggests that patients with severe mitral regurgitation may benefit from surgical treatment at an early, compensated stage. These results must be confirmed by a longer period of observation and should be viewed against the background of a western type of population and each institution's surgical expertise with mitral valve repair beyond the learning curve.

\section{REFERENCES}

1. Ross J. Left ventricular function and the timing of surgical treatment in valvular heart disease. Ann Intern Med 1981; 94(4 Pt 1)498-504.

2. Carabello BA, Nolan SP, McGuire LB. Assessment of preoperative left ventricular function in patients with mitral regurgitation: value of the end systolic wall stress-end systolic volume ratio. Circulation 1981;64:1212-7.

3. Perrier P, Deloche A, Chauvaud S, et al. Comparative evaluation of mitral valve repair and replacement with Starr, Björk, and porcine valve prostheses. Circulation 1984; 70(Suppl):I187-92.

4. Enriquez-Sarano M, Schaff HV, Orszulak TA, Tajik AJ, Bailey KR, Frye RL. Valve repair improves the outcome of surgery for mitral regurgitation: a multivariate analyis. Circulation 1995;91:1022-8.

5. Acar J, Michel PL, Luxereau P, Vahanian A, Cormier B. Indication for surgery in mitral regurgitation. Eur Heart $\mathrm{J}$ 1991;12(Suppl B):52-4.

6. Mudge GH. Asymptopmatic mitral regurgitation. When to operate? J Card Surg 1994;9(Suppl):248-51.

7. Cormier B, Starkman C, Enriquez-Sarano M, et al. L'échographie des insuffisances mitrales chirurgicales. Diagnostic 1ésionnel et prévision du type de chirurgie. Arch Mal Coeur 1990;83:345-50.

8. Lessana A, Tran Viet T, Ades F, et al. Mitral reconstructive operations: a series of 130 cases. J Thorac Cardiovasc Surg $1983 ; 86: 553-61$.

9. Kant O, Dijkstra JW, Huitinka H. Transesophageal color flow Doppler mapping in the assessment of mitral valvular regurgitation: comparisons with left ventricular angiography. J Am Soc Echocardiogr 1991;4:598-606.

10. Teicholz LE, Kreulen T, Herman MV, Gorlin R. Problems in echocardiographic volume determinations: echocardiographic-angiographic correlations in the presence or absence of asynergy. Am J Cardiol 1976;37:7-11.

11. Schiller NB. Two dimensional echocardiographic determination of left ventricular volume, systolic function, and mass: summary and discussion of the 1989 recommendations of the American Society of Echocardiography. Circulation 1991; 84(Suppl):I280-7.

12. Carpentier A. Cardiac valve surgery--The "French correction." J Thorac Cardiovase Surg 1983;86:323-37.

13. Lessana A, Escorsin M, Romano M, et al. Transposition of the posterior leaftet for treatment of ruptured main chordae 
of the anterior mitral leaflet. J Thorac Cardiovasc Surg 1985;89:804-5.

14. Edmunds LH, Clark RE, Coln LH, Miller CM, Weisel RD. Guidelines fo reporting morbidity and mortality after cardiac operations. J Thorac Cardiovasc Surg 1988;96:351-3.

15. Gaasch WH, John RM, Aurigemma GP. Managing asymptomatic patients with chronic mitral regurgitation. Chest 1995;108:842-7.

16. Acar J, Michel PL, Dorent R, et al. Evolution des valvulopathies opérées en France sur une période de 20 ans. Arch Mal Coeur 1992;85:411-5.

17. Waller BF, Morrow AG, Maron BJ, et al. Etiology of clinically isolated, severe chronic, pure mitral regurgitation: analysis of 97 patients over 30 years of age having mitral valve replacement. Am Heart J 1982;104:276-88.

18. Starling M. Effects of valve surgery on left ventricular contractile function in patients with long-term mitral regurgitation. Circulation 1995;92:811-8.

19. Kay GL, Aoki A, Zubiate P, Prejean CA, Ruggio JM, Kay JH. Probability of valve repair for pure mitral regurgitation. J Thorac Cardiovasc Surg 1994;108:871-9.

20. Lessana A, Carbone C, Romano M. Mitral valve repair: results and the decision-making process in reconstruction. $J$ Thorac Cardiovasc Surg 1990;99:622-30.

21. Ramanathan KB, Knowles J, Connor MJ, et al. Natural history of chronic mitral insufficiency: relation of peak systolic pressure/end systolic volume ratio to morbidity and mortality. J Am Coll Cardiol 1984;3:1412-6.

22. Delahaye JP, Gare JP, Viguier E, Delahaye F, De Gevigney G, Milon H. Natural history of severe mitral regurgitation. Eur Heart J 1991;12(Suppl B):5-9.

23. Deloche A, Jebara VA, Relland JYM, et al. Valve repair with Carpentier techniques: the second decade. J Thorac Cardiovasc Surg 1990;99:990-1002.

24. David TE, Armstrong S, Sun Z, Daniel L. Late results of mitral valve repair for mitral regurgitation due to degenerative disease. Ann Thorac Surg 1993;56:7-14.

25. Cohn LH, Couper GS, Aranki SF, Rizzo RJ, Kinchla NM, Collins JJ. Long-term results of mitral valve reconstruction for regurgitation of the myxomatous mitral valve. J Thorac Cardiovasc Surg 1994;107:143-51.

26. Sarano ME, Tajik JA, Schaff HV, Orszulak TA, Frye RL. Should repair of mitral regurgitation be performed in minimally symptomatic patients? Analysis of the impact of class III-IV symptoms on postoperative outcome [abstract]. J Am Coll Cardiol 1996:73A.

27. Jebara VA, Mihaileanu S, Acar C, et al. Left ventricular outflow tract obstruction after mitral valve repair: results of the sliding leaflet technique. Circulation 1993;88(Pt 2):30-4.

28. Lessana A, Herreman F, Boffety C, et al. Hemodynamic and cineangiographic study before and after mitral valvuloplasty (Carpentier's technique). Circulation 1981;64(Suppl):II195202.

29. Shyu KG, Chen JJ, Lin FY, et al. Regression of left ventricular mass after mitral valve repair of pure mitral regurgitation. Ann Thorac Surg 1994;58:1670-3.

30. Borow K, Green L, Mann T, et al. End-systolic volume as a predictor of postoperative left ventricular performance in volume overload from valvular regurgitation. Am J Med 1980;68:655-63.

31. Enriquez-Sarano M, Tajik AJ, Schaff HV, et al. Echocardiographic prediction of left ventricular function after correction of mitral regurgitation: results and clinical implications. J Am Coll Cardiol 1994;24:1536-43.

\section{Discussion}

Dr. Lawrence H. Cohn (Boston, Mass.). Dr. Dreyfus, you and your colleagues have presented some outstanding data on mitral valve repair. Along with similar studies, this information should allow us, with our cardiology colleagues, to expand our pool of patients for mitral valve repair. It is one of the first papers of this kind that I have seen focusing on this particular symptomatic class.

You have reported excellent results, with $1 \%$ mortality, freedom from death at 5 years of $98 \%$, thromboembolism, and reoperation. It would have been helpful to have compared this with the natural history of a similar group (mild or no symptoms) who were treated medically, but I do not believe you have that opportunity any longer.

To corroborate your results, I reviewed a personal series of 91 patients with class I and class II disease who underwent mitral valve repair just for floppy disease at the Brigham over the past 3 years. They had similar demographics, although they were slightly older and about $15 \%$ had concomitant coronary bypass. The operative mortality was zero. The thromboembolism and reoperation rates were exactly what you reported. My first question to you is this: Since you excluded associated operations, if you see a similar patient with myxomatous disease and concomitant coronary disease, do you still use the same indications for surgery that you mentioned in your paper, that is, a very early approach?

You suggest that surgical treatment may be feasible for a patient who has severe mitral regurgitation, no symptoms, and totally normal LV function. Is that what you now do in your practice? Would you suggest that this now be an indication for surgery, even in the totally normal LV with normal dimensions? Most cardiologists in the United States would observe such patients with normal function and normal volumes until volume changes or slight depression of ejection fraction occurred before allowing us to see patients, despite the fact that there are changes in the LV with relatively few symptoms. For example, in your series, how many had totally normal LV function and how many had very severe depression of LV ejection fraction, let's say, less than 0.30 ? Also, if the echocardiogram exhibits very severe anterior/posterior prolapse, which would require a lot of work and maybe a higher likelihood of valve replacement, and the patient is totally free of symptoms, does that patient in your series now still get this early operation? Others, including me, have suggested that transient atrial fibrillation or new-onset atrial fibrillation, despite good LV function, should be an indication for mitral valve repair. What have the preoperative and postoperative changes in atrial fibrillation been in this series? Finally, despite your using the rigid Carpentier ring for the annuloplasty, you seldom used the sliding repair technique in conjunction with this. Would you please comment on that?

These are superb results. Ideally, these kinds of data will stimulate our cardiologists to consider earlier referral of the symptom-free patient with severe mitral regurgitation.

Dr. Dreyfus. Thank you, Dr. Cohn. Obviously we could 
not do a study comparing natural history of mitral valve evolution as opposed to results with surgical treatment.

Your first question dealt with myxomatous disease associated with coronary disease. Treatment would depend on the severity of the coronary disease and the ejection fraction. For such patients coronary disease would probably be the predominant reason to recommend surgical treatment. If not the case, such patients would probably not undergo an operation at such an early stage because they are widely known to be at risk. However, we do believe that whatever the lesions are, mitral valve repair should be based on the severity of the regurgitation.

Totally normal LV function in combination with mitral regurgitation is a real problem. I do not think LV function should be taken into account with regard to symptoms because medical therapy can modify functional class. Most of the patients in western countries now have not only diuretics but also angiotensin-converting enzyme inhibitors, which can dramatically decrease the symptoms and allow the left ventricle to dilate silently. We do believe that regurgitation reaching the pulmonary veins at echocardiography is enough to predict and to indicate mitral surgery. As I have said before, patients may remain symptom-free for a long time although their ventricular size has increased. However, if a patient has a totally normal left ventricle we would perhaps adopt a strategy of close follow-up and recommend surgical treatment when the end-systolic diameter reached $40 \mathrm{~mm}$. I do not believe there were any ejection fractions in this series below $40 \%$.

Concerning the complexity of the lesions, so long as those patients have degenerative disease, we believe that mitral valve repair can be undertaken. Like Dr. Lessana, however, we are aware that there might be a risk of mitral valve replacement according to the complexity of the lesions, even in patients who are totally free of symptoms, and this risk would not be accepted by cardiologists here or in Europe.

We have not seen a significant change in the prevalence of atrial fibrillation in these patients before and after the operations. The infrequent use of the sliding repair is due to the multicenter effect. This technique was used in one center but not in the others. I think this policy has to be reconsidered. Three patients had systolic anterior motion, and it has been well demonstrated by Carpentier's group that the nonperformance of sliding repair is a risk factor for systolic anterior motion when the patient has a myxomatous valve and a high posterior leaflet.

Dr. Alain F. Carpentier (Paris, France). Because patients with severe mitral valve insufficiency can have a normal life for several years, they are not easy to convince, nor are the cardiologists. It seems to me that there are two conditions, the first being that we must be able to guarantee that we will be able to repair the valve rather than to replace it. Now comes my first question. I noticed that 64 of your patients had had valve replacement. Why was it not possible to predict that they could not have had a valve repair? Although the proportion is small, the question is important, particularly with the availability of echocardiography.

The second condition is to have a near-zero mortality.
Although your mortality was less than $1.7 \%$, you had at least two deaths that were due to so-called low cardiac output, or heart failure, which is a bit surprising for this particular group of patients. Any deaths in this particular group would be carefully analyzed, and I would like to .know a little bit more about these two deaths.

One important point was not emphasized: this is a multicenter study done by different surgeons, and it shows that this operation can be carried out safely by different surgeons and with reliable results.

Dr. Dreyfus. I would like to thank Professor Carpentier for his kind remarks and remind you that we have all learned mitral repair from him, in France at least.

Concerning the dimensions of the left ventricle, many cardiologists, like Mudge and Gaasch, have stressed that a rise in end-systolic diameter above $45 \mathrm{~mm}$ and an abnormal ejection fraction indicate ventricular dysfunction. Perhaps cardiologists do write things they do not believe, but at least they stress that ventricular dysfunction occurs very quickly, as soon as the LV end-systolic dimension increases mildly; therefore the absence of symptoms does not mean much.

To answer your first question, the 64 valve replacements were not done in patients who had no symptoms or mild symptoms. Over a period of 5 years, 584 patients underwent mitral valve operations. Among those, a vast majority had mitral valve repair and 64 had valve replacement. These statistics have nothing to do with class I or II disease.

Concerning the second question about the deaths, of course this is a real problem. One of the patients had a myocardial infarction, probably because of inadequate myocardial protection, and the other had LV dysfunction. Both of these patients, although having no symptoms or mild symptoms, had extremely enlarged left ventricles. The first one had a $78 \mathrm{~mm}$ end-diastolic dimension and the other one had an $83 \mathrm{~mm}$ dimension. These two patients emphasize the point that the ventricles can already be very dilated even if the patient has no symptoms or mild symptoms. Such patients can be very sick and operating on them is risky.

Dr. Manuel J. Antunes (Coimbra, Portugal). We have also been pushing our indications for mitral valve repair toward much earlier operations. Under the advice and encouragement of Professor Ballo, whose name remains forever connected to the mitral valve, we have undertaken repair on some patients who had mild or even minimal mitral valve regurgitation and had severe arrhythmias that were uncontrollable by medical therapy. These were mitral click syndromes. We repaired these valves by resecting areas of prolapsed leaflets or transposing chordae. The preliminary results were published some time ago and were encouraging. My question is this: Do you have any experience with mitral repair in this type of disease, and would you consider this as an indication for valve surgery in this type of patient?

Dr. Dreyfus. Thank you, Dr. Antunes. I'm sorry, but I do not have any data on that. We are looking forward in the future to answering this question, but not in this series. 